\title{
BIOÉTICA E DIREITOS DE PERSONALIDADE DO NASCITURO
}

\author{
Silmara J. A. Chinelato e Almeida*
}

SUMÁRIO: 1. Conceito de Nascituro. 2. Condição Jutídica do Nascituro: três teorias fundamentais. 3. Nascituros e Diteitos da Personalidade. 4. Direito à Vida. 5. Direito à Integridade Fisica. 6. Outros Direitos da Persondlidade: Direito à Imagem e Direito à Honra. 7. Direitos de Personalidade do Enbrião Pré-Implantatório 8. Bibliografia.

SUMMARY: 1. Concept of Unborn child. 2. Legal condition of the Unborn child: three basic theories. 3. Unborn children and Rights of Personality. 4. Right to Life. 5. Right to Physical Integrity. 6. Other Personality's Rights: Right to the Image and Right to Honor. 7 . Rights of Personality of the Preimplantatory Embryo. 8. Bibliography.

SUMARIO: 1. Concepto del naciente. Condición legal del naciente: tres teorias básicas. 3. Nacientes y los derechos de la personalidad. 4. Derecho a la Vida. 5. Derecho a la Integridad Física. 6. Otros derechos de la personalidad: Derecho a la imagen y a lo derecho a la honra. 7. Los derechos de la personalidad del embrión pret-implantatorio. 8. Bibliografia.

RESUMO: Nascituro é a pessoa por nascer, já concebida no ventre materno. No Brasil tem-se três correntes fundamentais acerca de sua natureza juridica: a natalista, em que se afirma que a personalidade civil começa do nascimento com vida, conforme o artigo $4^{a}$ do Código Civil, mas não explica as expectativas de direitos e baseta-se no Direito Romano, que naa considerava o nascituro como pessoa; a da personalidade condicional que reconhece a personalidade desde a concepção, mas condiciona ao nascimento com vida, deixando a margem os Direitos da Personalidade, tal como o direito a vida, que nấo depende do nascimento com vida e a concepcionista que sustenta que a personalidade começa da concepção. A personalidade não

\footnotetext{
* Doutora e Professora da Faculdade de Direito da Universidade de S. Paulo. Oorientadora credenciada no Curso de Pós-Graduacio (USP). Regente das disciplinas Diretro Civil, Direito Autoral e Direito do Consumidor. Advogada.
} 
se confunde com a capacidade e aquela năo é condicional, apenas certos direitos patrimoniais dependem do nascimento com vida. Os Direitos da Personalidade são as faculdades jurídicas cujo objeto são os diversos aspec tos da propria pessoa do sujeito, bem assim seus prolongamentos e projecões. O Código Civil não tutelou sob tal denominaça, mas reconhece-os em vários dispositivos. R. Limongi França classifica de forma tripartite os Direitos da Personalidade: Direito à Integridade Fisica, Direito a Integridade Moral é Direito à Integridade Intelectual. Classificamos em quatro categorias, colocando o Direito à Vida como categoria autônoma, não integrante do Dirtito à Integridade Física. O Direito à vida é o primordial e condicionante ja que sem este os outros inexistem. $O$ Direito à Integridade Física não se confunde com a da mâe e as diversas técnicas médicas intrauterinas demonstram esta preocupação com o nascituro en qualquer fase de desenvolvimento, aponta-se aqui a indenização de danos prématais previsto no Direito Estrangeiro. $O$ Direito à imagem diz respeito à reprodução fisica da pessoa, por qualquer meio de captaça, inchindo a ultra-sonografra. O Direito a honn existe desde o momento da concepcão. Assim, enfatiza-se que os Direitos da Personalidade iniciam-se desde a concepcão e ultrapassam a morte. O Direto de Personalidade do Embriào Pré-Implantatónio por constituir espécie do direito à identidade e opóe-se ao anonimato exigjdo dos doadores de gametas, sendo que a destruicão da identidade dos pais genéticos implica etr responsabilidade civil, por dano moral, pela violaça de direito da personalidade.

ABSTRACT: Unborn child is the person to being born, already conceived in the maternal womb. In Brazil there are three basic theories concenning its legal nature: the Natalist Theory, that affirms that the civil personality starts up with the birch with life, as the article 4 th of the Civil Code, but it does not explain the expecting rights and it is based on the Roman Law, that did not consider the unborn child as a person; the Theory of the conditional personality that recognizes personality since conception, but it is conditioned with the birth with lite, leaving to the edge the Rights of Personality, such as the right to life, that does not depend on the birth with life and the Concepcionist Theory that supports that personality starts with conception. The personality may not be confused with the capacity and that one is not conditional, only certain patrimonial rights depends on the birth with life. The Rights of Personality are legal faculties whose objects are the diverse aspects of citizen's proper person, as well its prolongations and projections. The Civil Code did not tutor such denominations, but it recognizes them in some devices. R. Limongi França classifies in a tripartite 
form the Rights of Personality: Right to Physical Integrity, Right to Moral Integrity and Right to Intellectual Integrity. We classify in four categories, placing the Right to Life as independent, not integrant category of the Right to Physical Integrity. The Right to life is primordial and it is conditional since without it the other rights do not exist. The unborn child's right to Physical Integrity must not be confused with the mother's and the diverse intrauterine medical techniques demonstrate this concern with the unborn child in any phase of development, for example, the indemnity of prenatal damages foreseen in foreign law. The Right to image concerns to physical reproduction, by any way of captation, including the extremeone. The Right to honor exists since conception. Thus, it is emphasized that the Rights of Personality are initiated since conception and exceed death. The Right of Personality of Pre-Implantatory Embryo for constituting species of the right to identity and opposes it the demanded anonymity of gametas' owners, being that the destruction of identity of genetic parents implies in civil liability, for pain and suffering, and to breaking of the right of personality.

RESUMEN: El naciente es la persona para nacer, concebida ya en la matriz maternal. En el Brasil existen tres teorías básicas referentes a su naturaleza legal: la teoría natalista, donde si afirma que el comienzo civil de la personalidad del nacimiento con vida, como el artículo $4^{a}$ del código civil, sino él no explica los derechos y lo que esperan se basa en lo Derecho Romano, que no consideraba lo naciente como persona; la teoría de la personalidad condicional que reconoce la personalidad desde el concepto, solamente condiciona el nacimiento con la vida, dejando al borde los derechos de la personalidad, tales como lo derecho a la vida, que no depende del nacimiento con vida y el concepcionista que apoya que el comienzo de la personalidad del concepto. La personalidad si no confunde con la capacidad y aquél no es condicional, sólo ciertos derechos patrimoniales dependen del nacimiento con vida. Los derechos de la personalidad son las facultades legales que tienen por objeto los diversos aspectos de la persona del ciudadano, así como sus prolongaciones y proyecciones. El código civil no tuteló tales denominaciones, sino que las reconoce en algunos dispositivos. $R$. Limongi França clasifica de la forma tripartita las derechas de la personalidad: Derecho a la Integridad Física, Lo Derecho a la Integridad Moral y a la Integridad Intelectual. Clasificamos en cuatro categorías, poniendo lo derecho a la vida como categoría independiente, no integrante de lo derecho a la integridad física. Lo derecho a la vida es primordial y el condicional una vez que sin esto los otros derechos inexisten. Lo derecho a la integridad fisica del naciente 
no si confunde con lo de la madte y las técnicas médicas intrauterinas diversas demuestran esta preocupación con el naciente en cualquier fase del desarrollo, punto aquí la indemnidad de los daños prenatales previstos en la ley extranjera. Lo derecho a la imagen dice respecto a la reproducción fisica de la persona, para cualquier manera de la captación, incluyendo las extremas. Lo derecho al honor existe desde el momento de la concepción. Así, se acentuia que los derechos de la personalidad están iniciados desde la concepción y exceden la muerte. Lo derecho de la personalidad del embrión pretimplantatorio para constituir la especie de lo derecho a la identidad y la opone el anonimato exigido de los donantes de gametas, siendo que la destrucción de la identidad de los padres genéticos implique en responsabilidad civil, por dolor y el sufrimiento, el romperse de lo derecho de la personalidad.

PALAVRAS CHAVES: Concepção Direito à Vida. Direito à Integridade Física. Direito à Integridade Moral. Direito à Integridade Intelectual. Embriâo.

KEY WORDS: Conception. Life's Law. Physics integrity's law. MoraI integrity's law. Intellectual integrity's law. Embryo.

PALABRAS LLAVE: Concepción. Derecho al Vida. Derecho al Integridad Fisica. Derecho al Integridad Moral. Derecho al Integridad Intelecto. Embrión.

\section{Conceito de Nascituro}

O tema nascituro é pouco tratado no Brasil, ao contrário do que ocorre em outros países. É relevante e atual, tendo em vista as novas técnicas médicas de reprodução humana assistida ou fertilização assistida e a engenharia genética.

Nascituro é a pessoa por nascer, já concebida no ventre materno. Tratando-se de fecundação "in vitro", que se realiza em laboratório, há necessidade de implantação do embrião "in anima nobile", para que se desenvolva, a menos que se o congele ou criopreserve, conforme nos ensinam os especialistas em reprodução humana assistida. A viabilidade de desenvolvimento depende, pois, da implantação no útero, onde se dará a nidação. Há mesmo, uma Recomendação (de n.o1.046, de 24.9.1986) do Conselho da Europa dirigida aos países-membros- mas esperando alcançar os demais- no sentido de proibição de experiências que visem a criar seres em laboratório (ectogênese), o que representa 
louvável preocupação. Com raízes no Direito Romano, o conceito de nascituro é o de pessoa por nascer, já concebida no ventre materno ("in anima nobile"). Há necessidade, no entanto, de que a legislação futura, civil e penal- na esteira da lei alemã, de 03 de dezembro de 1990 , que entrou em vigor em 1. a de janeiro de 1991 - proteja especificamente o embriäo pré-implantatório, assim denominado, enquanto "in vitro" ou crioconservado. O embrião pré-implantatório, é uma pessoa "in fieri", pois já dotado de carga genética própria, plenamente diferenciada quanto à do doador do sêmen e do óvulo.'

Cumpre observar que o direito constituendo poderá considerar como nascituro o embrião pré-implantatório. Dadas suas peculiaridades, parece-nos deva a legislação regular de modo diferente os direitos do nascituro implantado "in vivo" e o embrião pré-implantatório, que poderá ser denominado pré-nascituro.

\section{Condição Jurídica do Nascituro: três teorias fundamentais}

A despeito de inúmeras teorias sobre o início da personalidade e a condição jurídica do nascituro - muito bem sintetizadas por Pontes de Miranda em seu Tratado de Direito Privado, Parte Geral, Rio de Janeiro, Borsoi, 1954, t.I - podemos reduzi-las, ao menos no Brasil, em três correntes fundamentais: a natalista, a da personalidade condicional e a verdadeiramente concepcionista.

A primeira delas - natalista - encontra grande número de adeptos que afirmam que a personalidade civil começa do nascimento com vida, alicerçando-se na primeira parte do artigo $4^{a}$ do Código Civil que estatui:

"A personalidade civil do homem começa no nascimento com vida mas a lei põe a salvo desde a concepção, os direitos do nascituro".

Mencionada corrente não explica, no entanto, porque o mesmo artigo $4^{\underline{a}}$ reconhece direitos e não expectativas de direitos ao nascituro os quais, assim como os status, efetivamente lhe são atribuídos ao longo do Código, como, por exemplo,: status de filho (art. 458) de filho legítimo, segundo a terminologia adotada antes da Constituição Federal de 1988 (art. 337 e 338 ), direito de ser reconhecido antes do nascimento (parágrafo único do artigo 357 do Código Civil e parágrafo único do artigo 26 do Estatuto da Criança e do Adolescente), direito à curatela (458 e 462), à representação (462, caput combinado com arts. 383 , V e 385 ), direito de ser adotado (372).

'Assim o demonstra Jérome Lejeune in " $L$ ' encente concentrationaire- $d$ 'aprés les minutes du proces de Marythe". Éditions Le Surment, Fayard, Paris, 1990. 
Baseia-se, também, a corrente natalista, na errônea afirmação de que no Direito Romano o nascituro não era considerado pessoa, o que foi muito bem afastado pelo professor Titular de Direito Romano, Pierangelo Catalano, da Universidade de Roma (La Sapienza) em pesquisa específica a respeito da condição jurídica do nascituro, no Direito Romano, em suas várias fases, podendo-se citar, entre aquelas, o artigo "Os Nascituros entre - Direito Romano e o Direito Latino-americano (a propósito do art. $2^{a}$ do Projeto de Código Civil Brasileiro)" in Revista de Direito Civil, São Paulo, Revista dos Tribunais, 45/7-15, ano 12, julho a setembro de 1988.

A segunda corrente, denominada da personalidade condicional, reconhece a personalidade, desde a concepção, com a condição de nascer com vida. Constitui a corrente adotada por Clóvis Bevilacqua no art. $3^{\underline{a}} \mathrm{de}$ seu Projeto de Código Civil. O notável civilista pátrio, embora tenha-se aproximado bastante da teoria concepcionista, deixa à margem de suas indagações os Direitos da Personalidade - entre os quais se inclui, primordialmente, o direito à vida - direitos absolutos, incondicionais, não dependentes, pois, do nascimento com vida. ${ }^{2}$

Não se poderá afirmar, porém, que Clóvis Bevilacqua ,enquanto Doutrinador, fosse adepto da teoria da personalidade condicional, pois ao comentar o artigo 1537 do Código Civil, afirma que a indenização em caso de homicidio se estenderá aos filhos nascidos e nascituros, equiparando-os. ${ }^{3}$

É mister observar que o Projeto Bevilacqua, bem como o Código Civil brasileiro vigente, são datados de época em que entre nós não estava plenamente divulgada e alicerçada a Doutrina dos Direitos da Personalidade, falha na qual não incide o Projeto de Código Civil atual (Projeto $\mathrm{n}^{\mathrm{a}}$ 634-B, de 1975 - arts. 11 a 21 ).

A terceira corrente doutrinária é por nós denominada concepcionista ou verdadeiramente concepcionista, para diferenciar-se da teoria da Personalidade condicional. Sustenta que a personalidade começa da concepção e não do nascimento com vida, considerando que muitos dos direitos e status do nascituro não dependem do nascimento com vida, como os

\footnotetext{
${ }^{2}$ Assim se expressa Clóvis Bevilicqua in "Projecto do Código Cuyl Brasileiro- Trabalhos da Comissão Especial da Cámara dos Deputudos. Projectos primitivo e revisto". Rio de Janeiro, Imprensa Nacional, 1902, v. 1:

"Onde a verdade? Com aquelles que harmonizam o Direito Cryil consigo mesmo, com o penal, com a physiologia e com a logica, como demonstrou Teixeira de Freitas na luminosa nota ao artigo 221 de seu Esboģo. Realmente, si o nascituro é considerado sujeito de direitos, si a lei civil the confere um curador, si a lei criminal o protege cominando penas contra a provocaça de aborto, a lógica exige que se the reconheça o carater de pesson, como o fizeram os códigos e projectos acima citados, de acordo con os quaes se mostra Raoul de la Grasserie."

" "Código Civil Comentado." 3. ed, Rio de Janeiro, Francisco Alves, 1938, v. 4. 
Direitos da Personalidade, o direito de ser adotado, de ser reconhecido, atuando o nascimento sem vida como a morte, para os já nascidos.

Aperfeiçoando mencionada corrente, sustentamos em nossa tese de Doutorado e em trabalhos posteriores, que a personalidade - que não se confunde com capacidade - não é condicional. Apenas certos efeitos de certos direitos, isto é, os direitos patrimoniais materiais como a herança e a doação, dependem do nascimento com vida. A plenitude da eficácia desses direitos fica resolutivamente condicionada ao nascimento sem vida. O nascimento com vida, enunciado positivo de condição suspensiva, deve ser entendido, ao reverso, como enunciado negativo de uma condição resolutiva, isto é, o nascimento sem vida, porque a segunda parte do artigo $4^{\mathrm{a}}$, do Código Civil, bem como outros de seus dispositivos, reconhecem direitos (não, expectativas de direitos) e estados ao nascituro, não do nascimento com vida, mas desde a concepção.

O nascimento com vida aperfeiçoa o direito que dele dependa, dandothe integral eficácia, na qual se inclui sua transmissibilidade. Porém, a posse dos bens herdados ou doados ao nascituro pode ser exercida, por seu representante legal, desde a concepção, legitimando-o a perceber as rendas e os frutos, na qualidade de titular de direito subordinado à condição resolutiva. Fundamentam nosso entendimento os artigos 119, 1.186, 1.572, 1.778, todos os Códigos Civil e os artigos 877 e 878 do Código de Processo Civil, que cuidam da posse em nome do nascituro, como medida cautelar (ou processo de jurisdição voluntária, como preferem alguns processualistas).

Convém ressaltar importante contribuição dada pelo $R$. voto vencido do então Ministro do Supremo Tribunal Federal, Francisco Rezek, no RE no. 99.038-1-MG-j. em 18.10.83, DJ, 5, out. 1984. Ementário n. 1352-2 - quanto à não-taxatividade dos direitos do nascituro, razão porque entendia ser nula a compra e venda de ascendente a descendente, sem o consentimento do filho nascituro, por seu representante legal.

Entre os adeptos da corrente concepcionista, além de nós, incluímos: . Teixeira de Freitas (Consolidação das leis civis, 3. ed. Rio de Janeiro, H. Guarnier, 1886 e Esboço do Código Civil, Ministério da Justiça e Negócios Interiores, Serviço de Documentação, 1952), Pontes de Miranda (Tratado de direito privado; Parte Geral - Introdução - Pessoas físicas e jurídicas, Rio de Janeiro, Borsoi, 1954, t.1, e Tratado de direito privado; Parte especial - Direito de família - Direito parental - Direito protectivo, 
Rio de Janeiro, Borsoi, 1955, t.II), R.Limongi França (Manual de direito civil, 3. ed. São Paulo, Revista dos Tribunais, 1981),. Anacleto de Oliveira Faria e André Franco Montoro (Condição jurídica do nascituro no direito brasileiro, São Paulo, Saraiva, 1953) Ives Gandra da Silva Martins (Fundamentos do Direito Natural à vida, in Revista dos Tribunais, 623/ 27-30), Francisco dos Santos Amaral Neto (o Nascituro no Direito Civil Brasileiro. Contribuição do direito Português. Revista Brasileira de Direito Comparado, v.8, p.75-89), Forense, 1990), José Tavares (Os princípios fundamentais do direito civil, Coimbra, Coimbra Editora, 1928, v.2) Mario Emílio Bigotte Chorão ("O Problema da Natureza e tutela jurídica do Embrião Humano à luz de uma concepção Realista e Personalista do Direito", Separata da Revista "O Direito, Ano 123ª ., 1991, IV, Lisboa.

A tomada de posição no sentido de que o nascituro é pessoa importa reconhecer-lhe outros direitos, além dos que expressamente lhe são concedidos pelo Código Civil e outros diplomas legais, uma vez que se afasta na espécie, porque inaplicável, a regra de hermenêutica "exceptiones sunt strictissimae interpretationis." Reitera nosso modo de ver quanto à nãotaxatividade dos direitos reconhecidos ao nascituro, outro postulado hermenêutico, no sentido de que a enunciação taxativa é indicada expressamente pelas palavras só, somente, apenas e outras similares, inexistentes no artigo $4 .^{a}$ que, ao contrário, refere-se genericamente a "direitos" do nascituro.

Entre os que não são expressamente previstos, inclui-se o direito a alimentos, reconhecido ao "conceptus" desde o Direito Romano,conforme textos do Digesto 37, 9.1 ("De ventre in possessionem mittendo, et curatore ejus"). De fundamental importância, porque diretamente relacionado ao direito à vida e à integridade fisica- ambos Direitos da Personalidade - o direito a alimentos do nascituro,que visa à adequada assistência pré-natal, foi objeto de trabalho específico, de nossa lavra - Direito do Nascituro a Alimentos: do Direito Romano ao Direito Civil", Revista da PGE/SP, v.34/ 169-185.

\section{Nascituro e Direitos da Personalidade}

Conforme leciona R. Limongi França-"Manual de Direito Civil”,3.ed., SP, RT, 1981 e "Direitos da Personalidade. Coordenadas Fundamentais". Revista dos Tribunais, v. 567/9-16-Direitos da Personalidade "são as faculdades jurídicas cujo objeto são os diversos aspectos da própria pessoa 
do sujeito, bem assim seus prolongamentos e projeções. Uma vez mais pedimos vênia para nos fundamentar nas lições deste preclaro mestre ao tratar da natureza dos Direitos em tela. Conforme adverte o eminente civilista, a despeito de ser a lei a forma fundamental de expressão do Direito, outras existem, complementares, como reconhecido no artigo 4. ${ }^{2}$ da Lei de Introdução ao Código Civil. Criticando a posição positivista de Adriano De Cupis -"I Diritti della Personalità", Milano, 1950 - adverte: "Assim, além de Direitos Privados da Personalidade definidos em lei, outros há reconhecidos pelo costume e pelo Direito Científico. É o caso do Direito ao Nome, do Direito à Imagem, Do Direito Moral do Escritor." "O fundamento próximo da sua sanção é realmente a estratificação no Direito Consuetudinário ou nas conclusões da Ciência Jurídica. Mas o seu fundamento primeiro são as imposições da natureza das coisas, noutras palavras, o Direito Natural."

("Dircitos da Personalidade. Coordenadas Fundamentais". cit.,p.1)

A despeito de o Código Civil não ter tutelado sob tal denominação e de modo sistemático, os Direitos da Personalidade, reconhece-os , sim, , em vários dispositivos, como os artigos 1.537 a 1.553 ("Da liquidação das obrigações resultantes de atos ilícitos").

Cumpre anotar o relevante papel da Jurisprudência na tutela dos Direitos da Personalidade, ao considerar a existência de alguns deles não previstos expressamente no ordenamento jurídico brasileiro, como o direito à imagem, hoje consagrado no artigo $5 . \underline{a}$ incisos V, X e XXVIII, a da Constituição Federal. O reconhecimento- inclusive por parte do Supremo Tribunal Federal, conforme o demonstra acórdão inserto na RT 558/ 230, prolatado no R.E. n.o 91.328-9-SP-, do direito à imagem, com base nos ensinamentos da Doutrina nacional e estrangeira, atesta que não só a lei é forma de expressão do Direito.

Assentado que os Direitos da Personalidade são plenamente acolhidos no ordenamento jurídico brasileiro, em cuja abrangência se incluem a Doutrina ou Direito Científico, a Jurisprudência e a Lei - sendo irrelevante que não o sejam sob tal denominação, pelo Código Civil resta concluir que o nascituro é titular de Direitos da Personalidade, o que decorre da qualidade de pessoa, à qual são conferidos todos os direitos compatíveis com sua condição especial de estar concebido, no ventre materno e ainda não ter sido dado à luz. 
Divergindo apenas em parte- e não em substância- da classificação tripartite dada por R. Limongi França,nas obras retro mencionadas, aos Direitos da Personalidade, classificamo-los em quatro categorias fundamentais, colocando o Direito à Vida, como categoria autônoma, nãointegrante do Direito à Integridade Física, por ser um Direito condicionante, do qual dependem todos os demais.

Consideramos, destarte, a seguinte divisão quadripartite: Direito à Vida, Direito à Integridade Física, Direito à Integridade Moral e Direito à Integridade Intelectual.

\section{Direito à Vida}

O Direito primordial do ser humano é o direito à vida, por isso denominado direito condicionante, já que dele dependem os demais. Como bem esclarecer Antonio Chaves, em lição lapidar: "Existe um conjunto de normas que podem ser rastreadas em todas as legislações, quando não explícitas, nelas contidas implicitamente e que são tão essenciais que mal se concebem separadas do próprio conceito de civilização e de acatamento à pessoa humana. $O$ respeito à vida e aos demais direitos correlatos, decorre de um dever absoluto, por sua própria natureza, ao qual a ninguém é lícito desobedecer. (Tratado de Direito Civil,Parte Geral, 1. ed, SP, RT, 1982, v.1,t.1.,p.435).

Ainda que o direito à vida não fosse tutelado pelo sistema jurídico, sua natureza de Direito Natural legitimaria a imposição "erga omnes".

A Constituição Federal assegura no "caput"do artigo $5^{\mathrm{a}}$ - que define, não exaustivamente, os direitos e garantias fundamentais- a inviolabilidade do direito à vida, sem definir, no entanto, a partir de que momento se daria esta proteção. O inciso XXXVIII do mesmo artigo, reconhece a instituição do júri com competência para julgamento dos crimes dolosos contra a vida, entre os quais se inclui o aborto. Assegura, ainda, a licença à gestante, com a duração de cento e vinte dias, no artigo $6^{a}$, inciso XVI, a; proteção à maternidade, especialmente à gestante (art. 201, II e art. 203, I), com a finalidade de proteger a mãe e o nascituro. Cumpre salientar que até o texto final da Constituição vigente, a questão do início da vida foi objeto de inúmeras polêmicas-se a partir da concepção ou do nascimento - a que nos referimos em "O Nascituro no Código Civil e no nosso Direito Constituendo" in "O 
Direito de Família e a Constituição de 1988”, coordenado por Carlos Alberto Bittar, Saraiva, 1988, p.39-52. A definição expressa do início da vida, ficou, destarte, sob o encargo da legislação ordinária, embora pareça-nos que a Constituição Federal protege inequivocamente o nascituro.

No âmbito do Direito Penal, tutelam o direito à vida, os artigos 121 a 127 que incriminam o homicídio, o aborto e o infanticídio. Anote-se que, conforme observa com propriedade Walter Moraes, trata-se de exclusão de punibilidade, não, de exclusão de antijuridicidade. Por esta razão, segundo ele, o juiz não teria legitimidade para autorizar o aborto. ${ }^{4}$

No Direito Internacional o direito à vida do nascituro é expressamente previsto pela Convenção Americana dos Direitos Humanos, Pacto de S. José da Costa Rica,além de ter sido objeto das Recomendações n.os 934/82, 1.046/86 e 1.100/89 do Conselho da Europa.

O Pacto de San José da Costa Rica ou Convenção Americana de Direitos Humanos (1969) foi ratificado pelo Brasil aos 25 de setembro de 1992 e ingressou no Direito interno através do Decreto $\mathrm{n}^{\mathrm{a}}$ 678, de 06.11. 92. Estabelece no Capítulo II (Direitos Civis e Políticos), artigo $4^{a}$ - Direito à vida:

"1. Toda pessoa tem direito de que se respeite sua vida. Esse direito deve ser protegido pela lei e, em geral, desde o momento da concepção.Ninguém pode ser privado da vida arbitrariamente."

A seu turno, a Convenção sobre os Direitos da Criança (1989), ratificada pelo Brasil em 24 de setembro de 1990, considera em seu preâmbulo:

"Tendo em mente que, como indicado na Declaração sobre os Direitos da Criança, a criança, em razão de sua falta de maturidade física e mental necessita proteção e cuidados especiais, incluindo proteção jurídica apropriada antes e depois do nascimento;"

Conforme não passou desapercebido a Orlando Gomes nas "Considerações sobre a Liberalização do Aborto", in" Escritos Menores", Saraiva, 1981, pp.244-26O- ao civilista o exame da significação, natureza e consequências do aborto tem de ser feito à luz dos Direitos da Personalidade. Se se entende que o feto é "pars viscerum matris"- que no texto do Digesto apenas se referia à avaliação do parto da escrava, conforme

+ "Autorização judicial para o aborto" in Revista de Jurisprudência do Tribunal de Justiça de São Paulo v. 99.5 
observa Pierangelo Catalano, in Revista de Direito Civil v.45/7-15 -o problema consistirá em saber se a mãe tem o direito de dispor livremente de seu corpo. ${ }^{5}$ A solução oposta, é a dos que entendem que há no feto outra vida sobre a qual não se consente livre disposição. Esta é, no nosso modo de ver, a solução que encontra respaldo na Biologia e Genética e no Direito dos povos cultos. Como demonstrado pelos biólogos e geneticistas, a carga genética já está plenamente diferenciada, desde a fecundação, não se confundindo com a do pai nem com a da mãe, conforme leciona, com propriedade o biólogo Jose Botella LLusia no prólogo do livro de autoria de Gabriel del Estal, "Derecho a la Vida e Institucion Familiar", Eapsa, Madrid, 1979 , encontrando ressonância nas liçōes do médico francês Jérome Lejeune, especialista em Genética Fundamental e Professor da Universidade René Descartes de Paris, bem como partícipe da "Audição Pública sobre problemas jurídicos e éticos da genética humana com especial referência aos problemas relacionados com a engenharia genética", destinada a fundamentar as Resoluçôes do Parlamento Europeu sobre o assunto. $O$ desenvolvimento do nascituro, em qualquer dos estágios-zigoto, mórula, blástula, pré-embrião, embrião e feto- representa apenas um "continuum" do mesmo ser que não se modificará depois do nascimento, mas apenas cumprirá as etapas posteriores de desenvolvimento, passando de criança à adolescente, e de adolescente a adulto.

No mesmo sentido, o Conselho da Europa, na Recomendação 1046/ $86, n^{2} \cdot 5$, consigna:

Fin dalla fecondazione dell"ovulo la vita umana si sviluppa in modo continuo, sicché no si possono fare distinzioni durante le prime fasi del suo sviluppo."

Na Recomendação $1.100 / 89, \mathrm{n}^{\mathrm{a}} 7$, enfatiza: "l'embrione umano pur sviluppandosi in fasi successive indicate con definizioni differenti (zigote, morula, blastula, embrione pre-implantatorio, embrione, feto) manifesta comunque una differenziazione progressiva del suo organismo e, tuttavia, mantiene continuamente la propria identita biologica e genetica."

\footnotetext{
Nos Estados Unicos da Anérica o caso Roe v. Wade, de 1973, consagrou a tese no sentido de gue o aborto é un direito constitucional da mulher, fundado na 14.a Emenda que tutela o direito à privaci dade. Esta tese, no entanto, sofreu inúmeras críticas, tanto por parte da sociedude civil, como de juristas, entre os quais, alguns defensores do aborto, mas não sob tal fundamento. As decisões posteriores da Suprema Corte dos EUA indicam um entraquecimento da tese consagrada em Roe v. Wade, uma vez que impóe limitaçöes ao exercício do direito de abortar, inexistentes naquela decisão. A respeito ,consultem-se: Akron x Akron Center for Reproductive Health,462 U.S. 416 (1983), Tomburgh v. American College of Obstetricians and Gynecologists, 476 U.5.747 (1986) e Webster v. Reproductive Health Services, 109 S.CT. 3040 (1989). Hodgson y. Minnesota, 58 U.S.L. W. 4979 (6/26/90) e Oo v. Akron Ceater for Reproductive Health,58 U.S.L.W. $4979(6.26,90)$ discutem aborto da menor e problemas relatros ao consentimento dos pais.
} 
A lição de Tertuliano -" homo est qui est futurus, etiam fructus omnis iam in semine est" - parece sempre oportuna.

Cumpre salientar a importante contribuição dada por V. acórdão do $\mathrm{E}$. Tribunal de Justiça de S. Paulo, quanto ao reconhecimento do direito à vida do nascituro e a necessidade e possibilidade de assegurá-lo através da ação de investigação de paternidade cumulada com alimentos. Trata-se de acórdão proferido, por votação unânime, na Apelação Cível número 193.648-1 , julgada aos 14 de setembro de 1994, sendo Relator o eminente Desembargador Renan Lotufo (Revista de Jurisprudência do Tribunal de Justiça do Estado de S. Paulo, v. 150/ 90-95 e Revista dos Tribunais v. 703/ 60-63.

$\mathrm{O}$ reconhecimento do direito à vida, desde à concepção, mais pròpriamente denominado, "direito de viver" por Santos Cifuentes "Los Derechos Personalissimos", 1. ed., Lerner Ediciones, Buenos Aires, 1974 -importa, em regra, posição contrária ao aborto. Em circunstâncias como o perigo de vida da mãe, cede o direito à vida do nascituro, em favor daquela que, já integrada na família e na sociedade, e que talvez tenha a dela depender outras pessoas, o que caracteriza estado de necessidade, reconhecido pelo Direito Penal, bem como configura legítima defesa , consagrada no inciso I do artigo 160 do Código Civil.

\section{Direito à Integridade Física}

Desde a Antiguidade Clássica grega, Hipócrates e Aristóteles preocuparam-se com a Embriologia, ciência que informa a Perinatalogia - ramo da Medicina dedicada primariamente ao feto e ao recém-nascido. Ela, por sua vez, alcança hoje grande desenvolvimento através de novas técnicas como a amniocentese, a ultra-sonografia, a transfusão de sangue, na eritroblastose fetal (incompatibilidade sanguínea entre a mãe e o feto).

Estão em franco desenvolvimento, também, as cirurgias intra-uterinas das quais foi precursor Michael R. Harrison, da Universidade da Califórnia, S. Francisco, desde 1981, para corrigir uma obstrução da bexiga (uropatia obstrutiva), que o cirurgião conseguiu drenar, evitando, assim, a morte logo ao nascer. Em 1989, Harrison foi o primeiro a operar um feto portador de hérnia do diafragma que causa o desenvolvimento parcial ou mesmo impede o desenvolvimento do pulmão. Esta mesma técnica - que se encarta nas "cirurgias a céu aberto" - foi adotada com sucesso pelo Professor Bargy, do Hospital Saint-Vincent de Paul, em Paris. 
Em São Paulo, destacando-se o Hospital das Clinicas da Universidade de São Paulo em São Paulo, a Escola Paulista de Medicina, a Faculdade de Medicina de Ribeirão Preto, a Medicina Fetal desenvolve-se de modo relevante, através da técnica de catéteres, aplicada a encefalocentese (drenagem do cérebro), aplicada em caso de hidroencefalia e a do cordocentese (coleta de sangue do feto através da punção do cordão umbilical, para detectar doenças).

A diversidade de técnicas médicas intra-uterinas, inclusive cirurgias, indica que a Ciência se preocupa com o nascituro em qualquer fase de desenvolvimento, como ser autônomo e independente da mãe, procurando cada vez mais possibilitar-lhe o normal desenvolvimento, tendo por objetivo o nascimento perfeito.

Se o nascituro é pessoa, biológica e juridicamente, se sua integridade física e sua saúde não se confundem com as da mãe, ainda que com ela o concebido mantenha relação de dependência, não há como negar-lhe direito à integridade física e a saúde e deixar de inclui-lo no conceito de "ofendido" do artigo 1538 do Código Civil. Porque o direito à integridade física "lato sensu" - onde se incluem a integridade física "stricto sensu" e a saúde - é do nascituro e não da mãe, não é lícito a ela opor-se de tal direito. Assim sendo, não pode a mãe recusar-se a ingerir medicamento destinado a preservar a saúde do "conceptus" nem a submeter-se à intervenção médica que vise a dissolver medicamento no líquido amniótico que o feto engole instintivamente. Ainda que, na prática, tal recusa possa ensejar situações de fato de dificil solução, no ponto de vista jurídico ela se nos apresenta clara e inequívoca: não cabe à mãe dispor de direito à saúde que não é seu, mas, sim, do filho nascituro.

A proteção à saúde e à vida pré-natal é reconhecida pelo Direito Norte-Americano, não obstante consagre a liberalização do aborto, o que parece um contra-senso, já apontado por diversos autores. Cumpre observar a tendência atual de restringir tal direito o que é demonstrado pelas decisões posteriores ao caso Roe v. Wade, de 1971, conforme já se apontou na nota 5 supra.

Mesmo esta decisão reconhece que o aborto não é um direito absoluto pois devem ser considerados outros interesses. Em nome destes têm sido autorizados hospitais a fazer transfusões de sangue no feto, sem considerar as objeçôes religiosas dos pais. $\mathrm{O}$ direito à saúde e à vida do nascituro, nessas circunstâncias, tornam-se superiores ao direito de liberdade 
religiosa. A Suprema Corte de New Jersey assim decidiu em Hoener v. Bertinato (1961) e em Raleigh V. Fitkin Paul Morgan Memorial Hospital (1964), conforme relatado por William J. Maledon in "The law and the unborn child: the legal and logical inconsistencies", Notre Dame Lawyer, 46, p. 348-372.

A indenização de danos pré-natais, no Direito Estrangeiro, não é nova. Mesmo em sistemas juridicos que estabelecem o início da personalidade a partir do nascimento com vida, como o artigo $1^{\text {a }}$ do Código civil Italiano. A despeito de tal norma, uma notória sentença do Tribunal de Piacenza, de 3.7.1950-in Foro Italiano, 1951, I, \$987 - declara a responsabilidade dos pais, perante os filhos, quando thes transmitam uma doença, através da concepção, como a sífilis, que lhes reduza a capacidade física. No mesmo sentido, decisão de 1952, da Suprema Corte Federal Alemã, concede indenização a uma criança a quem foi transmitida a mesma doença, por transfusão à mãe grávida, de sangue contaminado. A despeito do $\S 1^{\text {a }}$ do B.G.B. estabelecer que a personalidade começa a partir do nascimento, o fundamento da decisão é o $\$ 823$ segundo o qual quem com dolo ou culpa causa dano à vida, ao corpo, a saúde à liberdade, à propriedade ou outro direito de outrem, é obrigado a ressarcir o dano.

Decorrente da premissa de que o nascituro tem personalidade desde a concepção- comprovada pela gravidez, conforme exigência das Ordenaçóes Filipinas, em harmonia com o Direito Romano e com respaldo nos artigos 877 e 878 do CPC, nas ações de posse em nome de Nascituros- no nosso modo de ver, não é necessário aguardar o nascimento com vida para o ajuizamento da ação.

Há casos em que a lesão ao direito à integridade física e à saúde deve cessar, sob pena de obstar o nascimento perfeito. Capacidade processual o nascituro tem, através de representação e com a intervenção do curador ao ventre ("curator ventris"). O interesse de agir é o dano iminente ou a lesão consumada, bem como o nexo causal cuja prova hoje é de relativa facilidade.

Cumpre acrescentar que, mesmo em épocas distantes em que ela não o era, a Suprema Corte de Columbia (DDC), em decisão pioneira e seguida, depois, pois 29 Estados, enfatizou a necessidade de se decidir o direito material que não poderia ser afastado pela dificuldade relativa da prova. Tratase do caso Bonbrest v. Kotz, de 1946, onde se requeria indenização por danos causados ao nascituro durante o parto, por erro médico, concedida 
pela Corte que, afastando a premissa, reconhecida falsa, de que o feto é parte do corpo da mãe, assentou ser ele independente dela, sem se indagar de sua viabilidade.

\section{Outros Direitos da Personalidade: Dircito à Imagem e Direito à Honra}

Todos os Direitos da Personalidade compativeis com a condição do nascituro, de pessoa por nascer, são reconhecidos. Assim - e com precedentes na Jurisprudência estrangeira- exemplicativamente, o direito à imagem e o direito à honra.

$O$ direito à imagem, do ponto de vista estritamente técnico e sem considerar o duplo sentido que the confere a Constituição Federal de 1988 , no artigo $5^{\text {a }}$ incisos $\mathrm{V}, \mathrm{X}$ e 28 , a, diz respeito à reprodução física da pessoa, inteira ou parcialmente, através de qualquer meio de captação: fotografia, vídeo, pintura. A ultrassonografia permite a reprodução do nascituro, o que importa a necessidade de consentimento do titular da imagem, por seu representante legal : o pai, ou a mãe ou o curador, conforme o caso (artigo 458 do Código Civil).

$O$ direito à honra existe desde o momento da concepção e é violado por exemplo, quando ao nascituro é imputada a bastardia. No Direito Inglês, a hipótese já foi decidida, conforme relata P.H.Winfield - "A text book of the law of tort", London, 1948, \$24.p.95 e seguintes, citado por Pietro Rescigno em "Il danno da procreazione", Rivista di Diritto Civile, Padova, Anno II, 1956, p.614-635.

No mesmo sentido, Santos Cifuentes- op.cit., p.631, nota 64- que, ao tratar de Direitos da Personalidade do nascituro, admite expressamente configurar-se violação ao direito à honra quando a ele é imputada a bastardia.

Cumpre enfatizar, uma vez mais, que os Direitos da Personalidade não começam com o nascimento nem terminam com a morte. Conforme vimos, iniciam-se desde a concepção e ultrapassam a morte. Se assim não fosse, a memória e a intimidade dos mortos não seria protegida. $\mathrm{O}$ Código Penal nos artigos 209 a 212 tipica os crimes contra o respeito aos mortos. O Código de Processo Penal admite, expressamente a revisão criminal em favor de pessoa falecida. (art.623). O Projeto de Código Civil, acolhendo a lição da Doutrina quanto à perpetuação dos Direitos da Personalidade, no artigo 12 expressamente consagra: 
"Pode-se exigir que cesse a ameaça, ou a lesão, a direito da personalidade, e reclamar perdas e danos, sem prejuízo de outras sanções previstas em lei.

Parágrafo único - Em se tratando de morto, terá legitimidade para requerê-la o cônjuge sobrevivente ou qualquer parente em linha reta, ou da colateral, até o quarto grau".

\section{Direitos de Personalidade do Embrião Pré-Implantatório}

Este tema será por nós desenvolvido em obra específica. Queremos, no entanto, enfatizar um dos vários direitos concernentes, de modo especial, ao embrião pré-implantatório - que pode ser considerado e denominado pré- nascituro, para diferenciar do implantado "in anima nobile" : direito à identidade genética.

Conforme afirmamos, mais de uma vez - inclusive na palestra proferida no Simpósio de Bioética e Biodireito promovido pelos RR.Conselho Nacional de Pesquisa e Pós-Graduação em Direito (Conpedi) e Universidade Estadual de Londrina, realizado nessa cidade, nos dias 25 a 27 de maio de 1997 - este direito constitui subespécie do direito à identidade. Relaciona-se, ainda, com o direito à verdade, reconhecido até então, aos filhos adotivos, sobre o qual tratou, com profundidade, Walter Moraes em sua monografia "Adoção e Verdade "- S. Paulo, RT, 1966.

$O$ direito à identidade genética, por ter a natureza jurídica de Direito de Personalidade, é inalienável, incessível, imprescritível, opondo-se, com primazia ao anonimato exigido dos e pelos doadores de gametas, segundo as normas éticas do Conselho Federal de Medicina (Resolução número 1.358, de 11 de novembro de 1992). Pode ou não ser exercido,segundo interesse do titular exclusivo, o filho gerado por técnica que utilize doador.

Sendo natural que nós, seres humanos, busquemos nossas raízes - por fatores vários, inclusive pela necessidade de melhor nos conhecermos não nos parece que esta busca da ascendência genética importe menos amor ou consideração aos pais civis.

Em que pese o respeito a opiniões contrárias, aplaudimos, pois , a legislação sueca e a espanhola que possibilitam ao filho conhecer seus pais biológicos, o que não importa desconstituição da paternidade, mas apenas exercício de um direito da personalidade.

Segundo pensamos, a destruição da identidade dos pais genéticos, por clinicas, hospitais e profissionais que se utilizem das técnicas de Reprodução 
Assistida com doação de gametas, sujeitá-los-á às regras da responsabilidade civil , por dano moral, por violação de direito da personalidade, com fundamento nos artigos 5.0 , inciso $\mathrm{V}$ e X da Constituição Federal e 159 do Código Civil.

\section{BIBLIOGRAFIA}

BEVILACQUA, Clóvis. Projecto do Código Civil Brasileiro- Trabalhos da Comissão Especial da Câmara dos Deputados. Projectos primitivo e revisto. Rio de Janeiro: Imprensa Nacional, v. 1, 1902.

Janeiro: Francisco Alves, v. 4, 1938.

Código Civil Comentado. 5. ed., Rio de

LEJEUNE, Jérome. L'enceite concentrationaire - d'aprés lês minutes du procès de Maryville. Paris: Éditions Le Surment, 1990.

MORAES, Walter. Autorização judicial para o aborto. In: Revista de Jurisprudência do Tribunal de Justiça de São Paulo. .99. 